Fothergill, P. G. \& Raine, L. C. D. P. (1954). J. gen. Microbiol. 10, 17-26.

\title{
The Mineral Nutritional Requirements of Mucor hiemalis Wehm.
}

\author{
By P. G. FOTHERGILL \\ Botany Department, King's College, Nervcastle upon Tyne \\ AND LAUREEN C. D. P. RAINE
}

Burn Laboratory, Royal Victoria Infirmary, Newcastle upon Tyne

SUMMARY: A series of four factorial experiments with culture media was carried out dealing with (1) the action of individual salts and their interactions in the medium, (2) the relation of the nitrogen source to the action of the salts, (3) the effect of the ratio of the carbon source and (4) the proportionate influence of the salts in the medium. Statistical analysis of the results has shown $(a)$ the composition of the culture medium which produces optimal growth under given conditions, $(b)$ that a suitable balance of salts in the medium, while conducive to good growth, is not of over-riding importance to this fungus, and (c) that ammonium nitrate serves as the key nutrient in the balance of salts which produces optimal growth measured as milligrams of dry weight.

The real study of the nutrition of fungi probably began when Raulin introduced his defined medium in 1869 . Since that time there have been numerous accounts of, and references to, fungal nutrition, but there is a lack of statistical investigations of the food requirements of fungi which are complete from one aspect of nutrition. Such investigations, which of necessity cover a limited. field, give a reliable picture of the behaviour or response of the fungi concerned expressed in some arbitrary but standard terms such as dry weight. The results are of value because they can serve as the basis for systematic comparisons under fixed and reproducible conditions of growth and for metabolic investigations which are becoming of increasing importance in the study of fungal physiology, and they also have an industrial application. As early as 1922, Young \& Bennett, using Macrosporium sarcineforme, Fusarium oxysporum and Phoma apicola with the salts calcium nitrate, acid potassium phosphate and magnesium sulphate at different molar concentrations, found that a correct balance of the mineral elements was essential for maximum growth, but that this behaviour varied according to the species of fungus used as test organism. Other workers have also obtained results indicative of a similar conclusion, until Talley \& Blank (1941) gave the results of their careful statistical analysis of the nutritional requirements of Phymatotrichum omnivorum, the causal organism of the root rot disease of cotton and other plants. These results showed that the absolute amount of certain essential metabolites was not so important as the balance between them. While the balance of salts may affect the overall metabolism of the fungus there are also indications that it may affect the synthesis of individual compounds such as penicillin. For instance, Pratt (1945) found that variations in the concentrations of $\mathrm{KH}_{2} \mathrm{PO}_{4}$, 
$\mathrm{MgSO}_{4}$ and $\mathrm{NaNO}_{3}$ affected the amount of penicillin produced by Penicillium notatum in surface cultures. It seems apparent, therefore, that the proportion of salts in a defined medium must be taken into account in order to obtain good growth of fungi. Moulds are now being used side by side with green plants as material for fundamental investigations in plant metabolism, and thus the nutritional requirements of the fungi used take on an added importance and become the starting point for some of these investigations. In this paper a critical study of the mineral food requirements of complementary strains of Mucor hiemalis is reported. No previous work on the nutrition of this fungus seems to have been done. The statistical work has been modelled on that of Talley \& Blank (1941) because their method simplifies interpretation of the results of the experiments.

\section{MATERIAL AND METHODS}

The complementary strains of $M$. hiemalis Wehm. used in this investigation were obtained from the Commonwealth Mycological Institute, Kew, cultures nos. 21216, 52 and 21217, 53. For general growth of stock cultures Blakeslee's agar was used (malt extract 20 g., glucose 20 g., peptone $1 \mathrm{~g}$. and agar 20 g., made up to a litre with water). For preliminary experiments the following basal defined liquid medium was used: glucose $20 \mathrm{~g}$., $\mathrm{MgSO}_{4} .7 \mathrm{H}_{2} \mathrm{O} 0.5 \mathrm{~g}$., $\mathrm{K}_{2} \mathrm{HPO}_{4} 1.0 \mathrm{~g}$., $\mathrm{KCl} 0.5 \mathrm{~g}$., $\mathrm{FeSO}_{4} 0.001 \mathrm{~g}$., $\mathrm{NH}_{4} \mathrm{NO}_{3} 1.6 \mathrm{~g}$,, and water to 1 litre. In all experiments the $\mathrm{K}_{2} \mathrm{HPO}_{4}$ was added aseptically and separately, after autoclaving, to the other constituents of the media. The inoculum for liquid cultures was prepared from fully mature sporing cultures on agar which were shaken with $10 \mathrm{ml}$. of sterile distilled water. Approximately $1 \mathrm{ml}$. of the resulting spore suspension was then used to inoculate each culture flask. It was found by trial that the exact amount of inoculum, provided it did not contain a very small number of spores, did not significantly affect the final dry weight.

Preliminary experiments showed that the optimum temperature for mycelial growth was $25^{\circ}$. The mycelial yield was also high at $20^{\circ}$, and this was the temperature used in these experiments. Although there was a slight difference in the rate of growth of the plus and minus strains consistent results were obtained in preliminary work when both strains were grown for 5 days. Analar chemicals were used throughout the work; the addition of 2 p.p.m. of $\mathrm{Zn}, \mathrm{Cu}, \mathrm{Co}, \mathrm{Mn}$ and $\mathrm{Mb}$ did not affect the results.

\section{RESULTS}

Factorial experiments were designed to study the concentration of the nutrient salts which might influence the results, and to assess the response brought about by the interaction of concentrations of two or three salts. The basis of the work is that the fungus is grown in all possible combinations of the salt concentrations chosen for study.

\section{First factorial analysis}

The first factorial experiment concerned the salts $\mathrm{KCl}, \mathrm{K}_{2} \mathrm{HPO}_{4}$ and $\mathrm{MgSO}_{4} .7 \mathrm{H}_{2} \mathrm{O}$. The $\mathrm{KCl}$ was present either at $0.002 \mathrm{M}$ or not added; it is always 
present in minute quantities in the chemicals used. The $\mathrm{K}_{2} \mathrm{HPO}_{4}$ was used at molar concentrations of $0.004,0.008$ and 0.012 , while the $\mathrm{MgSO}_{4} .7 \mathrm{H}_{2} \mathrm{O}$ was at molar concentrations of $0.0015,0.003$ and 0.006 . Thus there were eighteen possible combinations, and with five replicates each, making a total of ninety cultures in any one experiment. All cultures were grown for 5 days, the mycelial mat was filtered off, dried carefully just below $100^{\circ}$ to prevent charring, and weighed. All results were expressed as milligrams of dry weight.

The results of the first factorial experiment are given in Table 1, and the analysis of variance is contained in Table 2 . In this analysis odds of $99: 1$ are

Table 1. Growth responses of Mucor hiemalis $(+)$ and $(-)$ strains, to varying concentrations of $\mathrm{K}_{2} \mathrm{HPO}_{4}, \mathrm{MgSO}_{4}$ and $\mathrm{KCl}$

Results given as $\mathrm{mg}$. dry weight

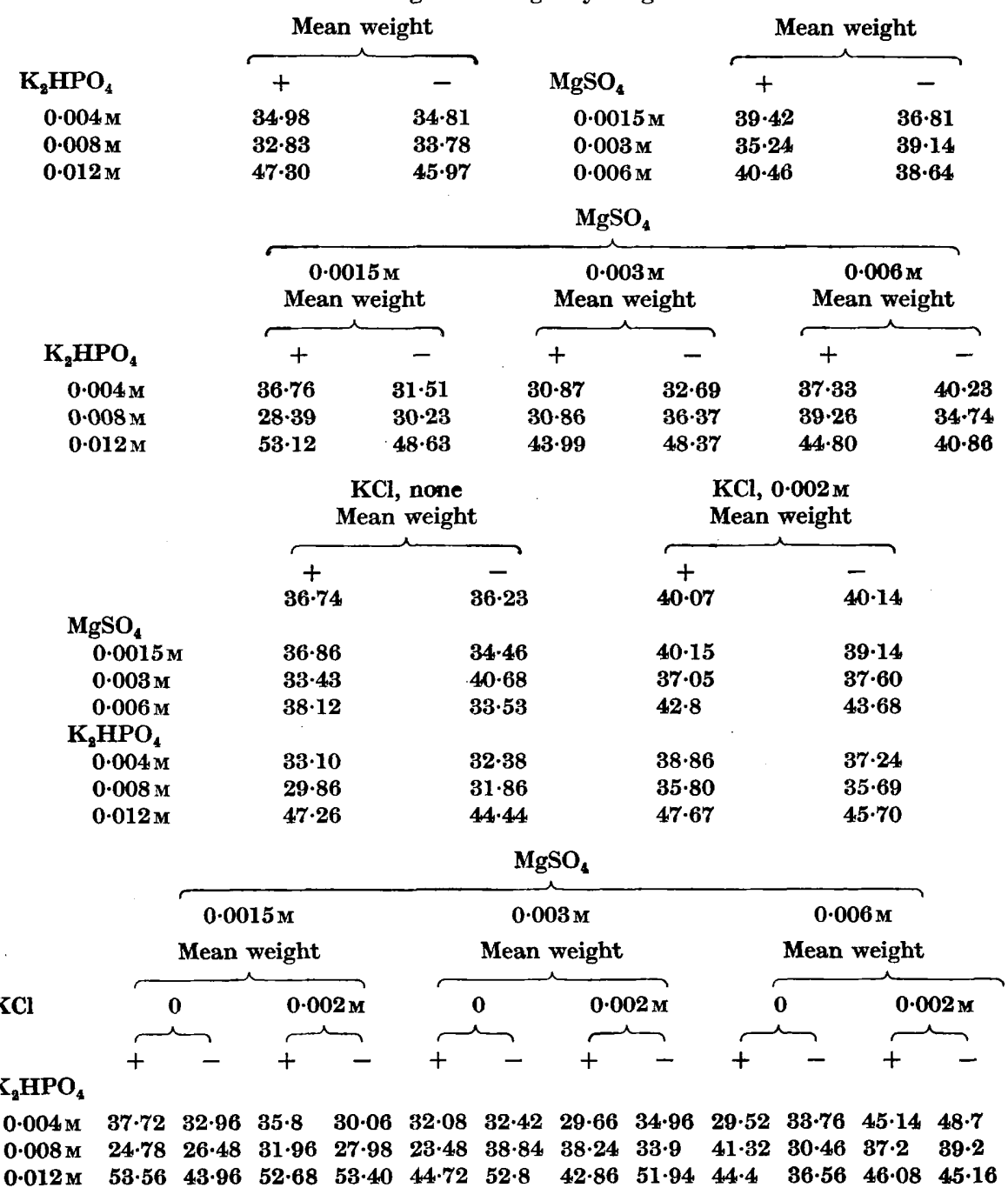


highly significant, while odds of $19: 1$ are taken as only being indicative of significance. Detailed consideration of these results is given below.

Magnesium sulphate; the plus and minus strains responded differently. The $F$ value for the $(+)$ strain indicates that the results are significant, while those for the (-) strain are not.

Dipotassium hydrogen phosphate; with both $(+)$ and $(-)$ strains the results are significant. An increase of $12 \cdot 3 \mathrm{mg}$. was obtained by increasing the molarity of $\mathrm{K}_{2} \mathrm{HPO}_{4}$ from 0.004 to 0.012 for the $(+)$ strain and a similar increase was seen for the (-) strain, which indicates that this molarity is favourable for this fungus.

Potassium chloride; the results for both strains agree closely, but the difference between the presence or absence of this salt is only of slight significance. A difference of only $4 \mathrm{mg}$. exists between the mean dry weights of $(+)$ and $(-)$ strains produced when this salt is present or absent. Chloride ions are therefore not required in these cultures or sufficient of the element may be present as impurity in the chemicals used.

\begin{tabular}{|c|c|c|c|c|c|}
\hline \multirow{3}{*}{$(+)$ strain } & \multirow{3}{*}{ D.F. } & \multirow{3}{*}{ Mean square } & \multirow{3}{*}{ Found } & \multicolumn{2}{|l|}{$F$} \\
\hline & & & & \multicolumn{2}{|c|}{ Required odds } \\
\hline & & & & $99: 1$ & $19: 1$ \\
\hline Total & 89 & $115 \cdot 14$ & - & - & - \\
\hline $\mathrm{MgSO}_{4}$ & $\mathbf{2}$ & $229 \cdot 33$ & $3 \cdot 806$ & 4.92 & $3 \cdot 13$ \\
\hline $\mathrm{K}_{2} \mathrm{HPO}_{4}$ & $\mathbf{2}$ & 1828.04 & $30 \cdot 43$ & 4.92 & $3 \cdot 13$ \\
\hline $\mathrm{KCl}$ & 1 & $238 \cdot 1$ & $3 \cdot 968$ & $7 \cdot 01$ & $\mathbf{3 \cdot 9 8}$ \\
\hline $\mathrm{MgSO}_{4} \times \mathrm{KCl}$ & $\mathbf{2}$ & $6 \cdot 61$ & $\ldots$ & - & - \\
\hline $\mathrm{K}_{3} \mathrm{HPO}_{4} \times \mathrm{KCl}$ & 2 & $65 \cdot 7$ & 1.09 & 4.92 & $3 \cdot 13$ \\
\hline $\mathrm{K}_{2} \mathrm{HPO}_{4} \times \mathrm{MgSO}_{4}$ & 4 & $239 \cdot 34$ & 3.97 & $\mathbf{3 \cdot 6}$ & $2 \cdot 5$ \\
\hline Error & 76 & $60 \cdot 25$ & - & - & - \\
\hline \multicolumn{6}{|l|}{$(-)$ strain } \\
\hline Total & 89 & $105 \cdot 88$ & - & - & 一 \\
\hline $\mathrm{MgSO}_{4}$ & $\mathbf{2}$ & - & - & - & - \\
\hline $\mathrm{K}_{2} \mathrm{HPO}_{4}$ & 2 & $1371 \cdot 02$ & $16 \cdot 48$ & 4.92 & $3 \cdot 13$ \\
\hline $\mathrm{KCl}$ & 1 & 344.96 & $4 \cdot 15$ & 7.01 & 3.98 \\
\hline $\mathrm{MgSO}_{4} \times \mathrm{KCl}$ & 2 & - & - & - & - \\
\hline $\mathrm{K}_{2} \mathrm{HPO}_{4} \times \mathrm{KCl}$ & 2 & $6 \cdot 12$ & - & - & - \\
\hline $\mathrm{K}_{2} \mathrm{HPO}_{4} \times \mathrm{MgSO}_{4}$ & 4 & - & - & - & - \\
\hline Error & 76 & $83 \cdot 21$ & - & - & - \\
\hline
\end{tabular}

Interaction of salts of the first analysis

This experiment also shows the interaction of the first and second order of salts, i.e. the salts taken in the three possible pairs and all together. The results of the first and second order interactions are also given in Tables 1 and 2.

There is a divergence of response between the two complementary strains of Mucor regarding the interaction of $\mathrm{MgSO}_{4} .7 \mathrm{H}_{2} \mathrm{O}$ and $\mathrm{K}_{2} \mathrm{HPO}_{4}$. With the (-) strain the results show no significance, but with the $(+)$ strain there is significance. The response of $M$. hiemalis $(+)$ strain is most marked when the $\mathrm{MgSO}_{4} .7 \mathrm{H}_{2} \mathrm{O}$ is at the lowest concentration of $0.0015 \mathrm{M}$. The average dry 


\section{Mineral requirements of Mucor hiemalis}

weight then produced was $53.12 \mathrm{mg}$., which was $8.32 \mathrm{mg}$. greater than the next highest weight. The lower level of $\mathrm{MgSO}_{4} .7 \mathrm{H}_{2} \mathrm{O}$ did not influence the response of $0.005 \mathrm{M}$ - and $0.008 \mathrm{M}-\mathrm{K}_{2} \mathrm{HPO}_{4}$, but it did affect the response to $0.012 \mathrm{M}$ $\mathrm{K}_{2} \mathrm{HPO}_{4}$. At all levels an increase of growth results with increase of phosphate concentration to the highest level of $0.012 \mathrm{~m}$. The conclusion to be drawn is that it is a special balance between these two salts which is important in increasing the amount of growth. In their experiments with Phymatotrichum omnivorum, Talley \& Blank (1941) also found that the correct physiological balance between $\mathrm{K}_{2} \mathrm{HPO}_{4}$ and $\mathrm{MgSO}_{4} \cdot 7 \mathrm{H}_{2} \mathrm{O}$ was a deciding factor in increasing growth of the fungus. In their case growth increased as the concentration of both salts increased, whereas with $M$. hiemalis $(+)$ strain growth increased with the lowest level of $\mathrm{MgSO}_{4} \cdot 7 \mathrm{H}_{2} \mathrm{O}$ combined with the highest level of $\mathrm{K}_{2} \mathrm{HPO}_{4}$.

The interaction of $\mathrm{K}_{2} \mathrm{HPO}_{4}$ and $\mathrm{KCl}$ is not significant, but an increased growth is shown for both $(+)$ and $(-)$ strains when $\mathrm{KCl}$ was added at the lower levels of $0.004 \mathrm{M}$ - and $0.008 \mathrm{M}-\mathrm{K}_{2} \mathrm{HPO}_{4}$. The single salt analysis indicated that the action of the chloride ion in growth is doubtful when added as $\mathrm{KCl}$ with potassium already present. Hence the result of the first order interaction of $\mathrm{KCl}$ and $\mathrm{K}_{2} \mathrm{HPO}_{4}$ probably indicates that at the lower levels of $\mathrm{K}_{2} \mathrm{HPO}_{4}$, potassium becomes a limiting factor, and that the deficiency is made up by addition of $\mathrm{KCl}$.

With the $(+)$ strain the interaction of $\mathrm{MgSO}_{4} \cdot 7 \mathrm{H}_{2} \mathrm{O}$ and $\mathrm{KCl}$ was not significant, while with the (-) strain the results indicate no significance for the interaction of any of the salts used. As regards the third order of interaction, i.e. between the three salts taken together, the results above indicate that this interaction is not significant since only one of the first order interactions proved to be so.

\section{Second factorial analysis}

It has been noted by various workers that the source of the nitrogen available to fungi during growth is often important for development. In 1937, Robbins, as a result of a comprehensive study, was able to classify fungi into four groups according to their nitrogen requirements as follows : (a) those fungi able to fix atmospheric nitrogen and also able to use organic and inorganic sources of the elements, $(b)$ those which use only organic nitrogen and also ammonium and nitrate nitrogen, $(c)$ those which use only inorganic and ammonium nitrogen, and $(d)$ those which use only organic nitrogen. Although such classification is to a large extent arbitrary, it nevertheless becomes of the greatest importance to study the nitrogen source in any analysis of the growth requirements of a given fungus.

The first factorial experiment indicated conclusively that $\mathrm{K}_{2} \mathrm{HPO}_{4}$ and $\mathrm{MgSO}_{4} \cdot 7 \mathrm{H}_{2} \mathrm{O}$ were necessary for good growth of $M$. hiemalis, and in order to obtain a high yield in terms of dry weight under the conditions of the experiment these salts should be given at concentrations of $0.012 \mathrm{M}$ and $0.0015 \mathrm{M}$ respectively. Hence in the second factorial experiment described below the salts were used at these concentrations for both $(+)$ and $(-)$ strains, although no statistical significance was found for the $(-)$ strain as regards the utiliza- 
tion of $\mathrm{MgSO}_{4} .7 \mathrm{H}_{2} \mathrm{O}$. In this second experiment the object was to evaluate the amount of growth and to see whether a balance of salts is important when the nitrogen source is $\mathbf{N H}_{4} \mathrm{NO}_{3}$. Preliminary work showed this salt to be favourable for the growth of the fungus used; it is important to note, however, that both component radicles can supply nitrogen to the fungus.

Table 3. Growth responses of Mucor hiemalis (+) and (-) strains to varying concentrations of $\mathrm{K}_{2} \mathrm{HPO}_{4}, \mathrm{NH}_{4} \mathrm{NO}_{3}$ and $\mathrm{MgSO}_{4}$

Results given as mg. dry weight

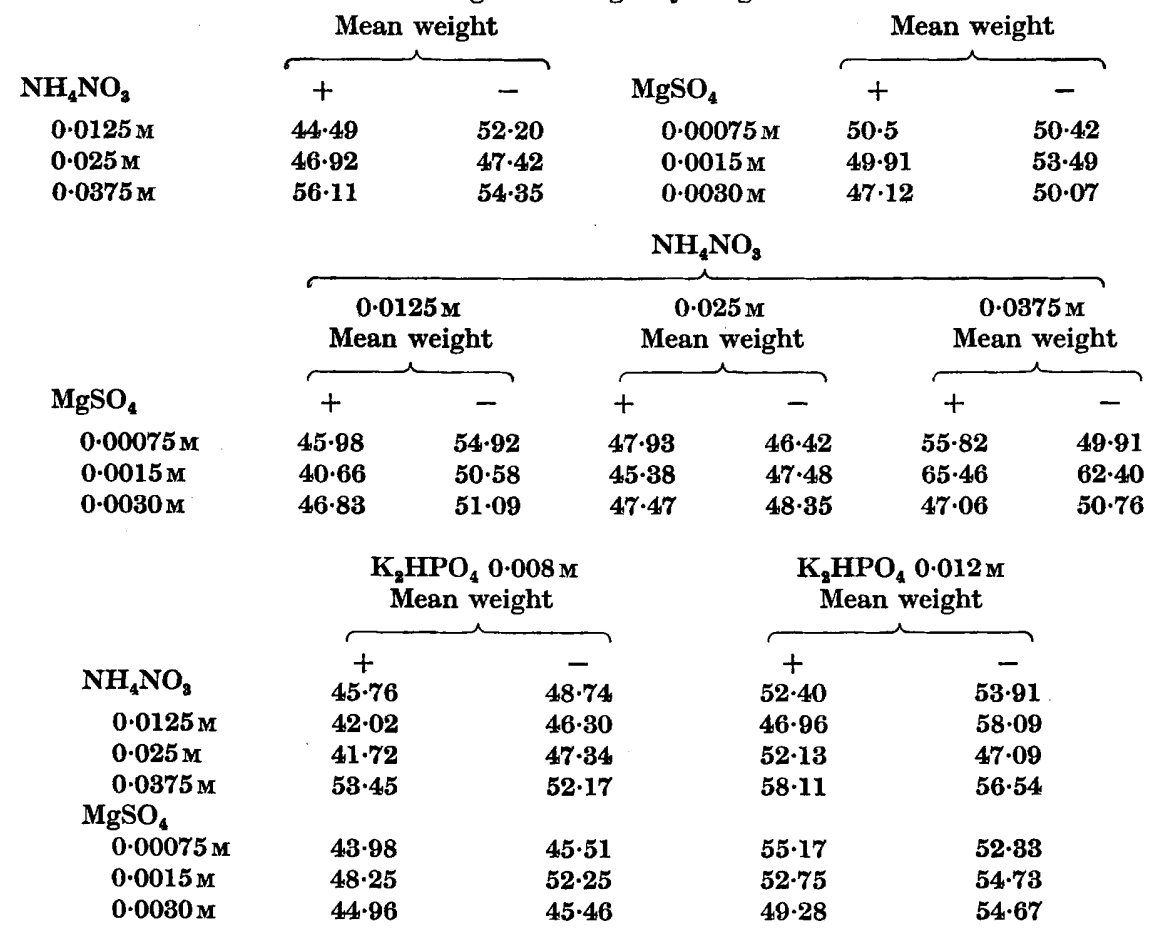

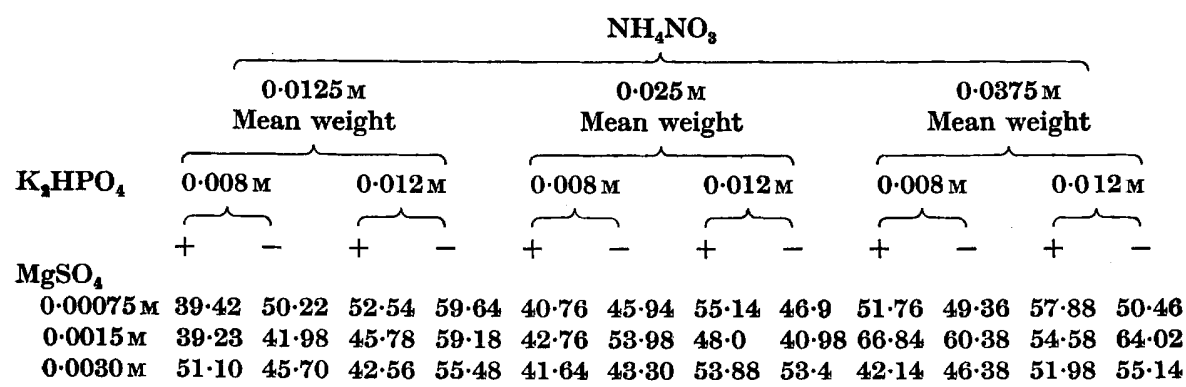

The experimental procedure in this second analysis was similar to that in the first. $\mathrm{K}_{2} \mathrm{HPO}_{4}$ was used at two levels, $0.008 \mathrm{M}$ and $0.012 \mathrm{M} ; \mathrm{MgSO}_{4} .7 \mathrm{H}_{2} \mathrm{O}$ was used at three levels, $0.00075 \mathrm{M}, 0.0015 \mathrm{M}$ and $0.003 \mathrm{M}$; while $\mathrm{NH}_{4} \mathrm{NO}_{3}$ was used at three levels, $0.0125 \mathrm{M}, 0.025 \mathrm{M}$, and $0.0375 \mathrm{M}$. The results of the experiment expressed as a summary of the mean dry weights are given in Table 3, and the 
analysis of variance is seen in Table 4. The probability levels are again $99: 1$ and $19: 1$. Detailed consideration of the results is given below.

Dipotassium hydrogen phosphate; the analysis of variance shows that the results for both strains of the fungus are significant. The $0 \cdot 012 \mathrm{~m}$ solution again gave the best dry weight, but the mean dry weight for the $0.008 \mathrm{M}$ solution was greater than in Experiment 1.

Magnesium sulphate; the response of the two strains differed greatly. For the $(+)$ strain, while the actual dry weights are little different from one another at the levels of the salt, the analysis of variance indicates significance. The highest of the dry weights is given by the lowest level of the salt, i.e. by $0.00075 \mathrm{M}$. The results for the $(-)$ strain are not significant.

Ammonium nitrate; increasing concentrations of this salt produced significantly increasing growth responses for the $(+)$ strain. Again the $(-)$ strain behaves rather differently but the $F$ value is still significant.

\section{Interaction of salts of the second analysis}

The results for the physiological interaction of $\mathrm{K}_{2} \mathrm{HPO}_{4}$ and $\mathrm{MgSO}_{4} \cdot 7 \mathrm{H}_{2} \mathrm{O}$ are highly significant. The greatest mean dry weight was obtained with $0.012 \mathrm{M}-\mathrm{K}_{2} \mathrm{HPO}_{4}$ when the concentration of $\mathrm{MgSO}_{4} 7 . \mathrm{H}_{2} \mathrm{O}$ was at its lowest level. This result agrees closely with that of the first factorial experiment and indicates that it is a balance between these two salts which is important and not the concentration of either one of them. Thus a decrease in $\mathrm{MgSO}_{4} \cdot 7 \mathrm{H}_{2} \mathrm{O}$ without a corresponding increase in $\mathrm{K}_{2} \mathrm{HPO}_{4}$ would not have resulted in an increase of dry weight. The results for the (-) strain are not statistically significant, but the average yields for the various concentrations are of the same order as those for the $(+)$ strain.

Table 4. Analysis of variance. Exp. 2

\begin{tabular}{|c|c|c|c|c|c|}
\hline \multirow{3}{*}{ (+) strain } & \multirow[b]{3}{*}{ D.F. } & \multirow[b]{3}{*}{ Mean square } & \multicolumn{3}{|c|}{$\boldsymbol{F}$} \\
\hline & & & \multirow[b]{2}{*}{ Found } & \multicolumn{2}{|c|}{ Required odds } \\
\hline & & & & $99: 1$ & $19: 1$ \\
\hline Total & 89 & $97 \cdot 09$ & 一 & - & 一 \\
\hline $\mathrm{K}_{8} \mathrm{HPO}_{4}$ & 1 & $1002 \cdot 0$ & $39 \cdot 92$ & $7 \cdot 01$ & $3 \cdot 98$ \\
\hline $\mathrm{MgSO}_{4}$ & $\mathbf{2}$ & $91 \cdot 55$ & $3 \cdot 65$ & 4.92 & $3 \cdot 13$ \\
\hline $\mathrm{NH}_{4} \mathrm{NO}_{3}$ & 2 & $1058 \cdot 9$ & $42 \cdot 19$ & $4 \cdot 92$ & $3 \cdot 13$ \\
\hline $\mathrm{K}_{2} \mathrm{HPO}_{4} \times \mathrm{MgSO}_{4}$ & 2 & $744 \cdot 8$ & $29 \cdot 67$ & 4.92 & $\mathbf{3} \cdot 13$ \\
\hline $\mathrm{K}_{2} \mathrm{HPO}_{4} \times \mathrm{NH}_{4} \mathrm{NO}_{3}$ & 2 & $78 \cdot 82$ & $3 \cdot 14$ & $4 \cdot 92$ & $\mathbf{3 \cdot 1 3}$ \\
\hline $\mathrm{NH}_{4} \mathrm{NO}_{3} \times \mathrm{MgSO}_{4}$ & 4 & $446 \cdot 03$ & $17 \cdot 77$ & $3 \cdot 6$ & $\mathbf{2 \cdot 5}$ \\
\hline $\begin{array}{l}\text { Error } \\
\qquad(-) \text { strain }\end{array}$ & 76 & $25 \cdot 1$ & - & 一 & - \\
\hline Total & 89 & $120 \cdot 09$ & 一 & - & - \\
\hline $\mathrm{K}_{2} \mathrm{HPO}_{4}$ & 1 & $601 \cdot 14$ & $6 \cdot 1$ & $7 \cdot 01$ & $\mathbf{3 \cdot 9 8}$ \\
\hline $\mathrm{MgSO}_{4}$ & $\mathbf{2}$ & $111 \cdot 52$ & $\mathbf{1 \cdot 2}$ & $4 \cdot 92$ & $3 \cdot 13$ \\
\hline $\mathrm{NH}_{4} \mathrm{NO}_{3}$ & $\mathbf{2}$ & $383 \cdot 69$ & $\mathbf{3 \cdot 9}$ & $4 \cdot 92$ & $\mathbf{3} \cdot \mathbf{1 3}$ \\
\hline $\mathrm{K}_{2} \mathrm{HPO}_{4} \times \mathrm{MgSO}_{4}$ & 2 & $95 \cdot 54$ & 0.9 & $4 \cdot 92$ & $\mathbf{3} \cdot \mathbf{1 3}$ \\
\hline $\mathrm{K}_{2} \mathrm{HPO}_{4} \times \mathrm{NH}_{4} \mathrm{NO}_{3}$ & 2 & $293 \cdot 85$ & $\mathbf{3} \cdot \mathbf{0}$ & $4 \cdot 92$ & $3 \cdot 13$ \\
\hline $\mathrm{NH}_{4} \mathrm{NO}_{3} \times \mathrm{MgSO}_{4}$ & 4 & 220.56 & $\mathbf{2 \cdot 3}$ & $3 \cdot 60$ & $2 \cdot 5$ \\
\hline Error & 76 & $97 \cdot 84$ & - & - & - \\
\hline
\end{tabular}


The analysis of variance for the interaction of $\mathrm{K}_{2} \mathrm{HPO}_{4}$ and $\mathrm{NH}_{4} \mathrm{NO}_{3}$ shows significance at the lowest level of probability. The interaction is such that the best dry weight due to increased phosphate was only obtained with the highest concentration of $\mathrm{NH}_{4} \mathrm{NO}_{3}$. The results for the $(-)$ strain again are not significant, but again the average yields are high and of the same order as those for the complementary strain.

In the results of the first-order interaction of $\mathrm{NH}_{4} \mathrm{NO}_{3}$ and $\mathrm{MgSO}_{4} .7 \mathrm{H}_{2} \mathrm{O}$ a high $F$ value was obtained and all the dry weights were well above the average dry weights for other interactions and salts used. Table 3 shows that a very high dry weight of $65.46 \mathrm{mg}$. is obtained with $0.0375 \mathrm{M}-\mathrm{NH}_{4} \mathrm{NO}_{3}$ and $0.0015 \mathrm{M}-\mathrm{MgSO}_{4}$. It is also seen that in the second order interaction the concentration of $\mathrm{K}_{2} \mathrm{HPO}_{4}$ does not greatly influence the relationship between $\mathrm{NH}_{4} \mathrm{NO}_{3}$ and $\mathrm{MgSO}_{4} \cdot 7 \mathrm{H}_{2} \mathrm{O}$. The results for the (-) strain are also significant. The combination of $0.0375 \mathrm{M}-\mathrm{NH}_{4} \mathrm{NO}_{3}$ and $0.0015 \mathrm{M}-\mathrm{MgSO}_{4}$ gave the highest dry weight, and the concentration of $\mathrm{K}_{2} \mathrm{HPO}_{4}$ again does not seem to affect the response in respect to the balance between these two salts.

The analysis of the two factorial experiments described so far enables us to conclude $(a)$ that a balance between the salts used is desirable, and $(b)$ that the following solution will yield a high dry weight when supplied to either the $(+)$ or the (-) strain of $M$. hiemalis: $0.0375 \mathrm{M}-\mathrm{NH}_{4} \mathrm{NO}_{3}, 0.012 \mathrm{M}-\mathrm{K}_{2} \mathrm{HPO}_{4}$ and $0.0015 \mathrm{M}-\mathrm{MgSO}_{4} \cdot 7 \mathrm{H}_{2} \mathrm{O}$. The balance between the salts falls into two categories, firstly that between $\mathrm{K}_{2} \mathrm{HPO}_{4}$ and $\mathrm{MgSO}_{4} .7 \mathrm{H}_{2} \mathrm{O}$ and secondly that between $\mathrm{MgSO}_{4} .7 \mathrm{H}_{2} \mathrm{O}$ and $\mathrm{NH}_{4} \mathrm{NO}_{3}$. Initially a high level of phosphate is necessary to increase the dry weight, but given that high level the highest growth response is obtained when the balance between the other two salts is correct.

\section{Third factorial analysis}

In the experiments already described carbon was supplied as glucose at the $\mathbf{2} \%$ level. It was possible that an increase in the concentration of the carbon source might improve the yield estimated as dry weight. Hence an experiment was designed in which two levels of $\mathrm{NH}_{4} \mathrm{NO}_{3}$ were combined with three levels of glucose. Thus $\mathrm{NH}_{4} \mathrm{NO}_{3}$ was supplied in concentrations of $0.025 \mathrm{M}$ and $0.0375 \mathrm{M}$ and glucose at 2,4 and $6 \%$ levels. The summary of the results of the experiment is given in Table 5 .

From these results it is obvious that the limiting factor at all levels of glucose concentration is the $\mathrm{NH}_{4} \mathrm{NO}_{3}$ concentration. But at the higher sugar levels,

Table 5. Summary of the response of Mucor hiemalis (+) and (-) strains to concentrations of glucose and ammonium nitrate

Results given as mg. dry weight

\begin{tabular}{|c|c|c|c|c|}
\hline \multirow[b]{2}{*}{ Strain } & \multirow{2}{*}{$\begin{array}{c}\text { Ammonium } \\
\text { nitrate }\end{array}$} & \multicolumn{3}{|c|}{ Glucose \% } \\
\hline & & 2 & 4 & 6 \\
\hline$(+)$ & $\begin{array}{l}0.025 \mathrm{M} \\
0.0375 \mathrm{M}\end{array}$ & $\begin{array}{l}48 \cdot 0 \\
64 \cdot 5\end{array}$ & $\begin{array}{l}26 \cdot 6 \\
62 \cdot 1\end{array}$ & $\begin{array}{l}30 \cdot 2 \\
64.5\end{array}$ \\
\hline$(-)$ & $\begin{array}{l}0.025 \mathrm{M} \\
0.0375 \mathrm{M}\end{array}$ & $\begin{array}{l}40.9 \\
64 \cdot 0\end{array}$ & $\begin{array}{l}27 \cdot 1 \\
55 \cdot 9\end{array}$ & $\begin{array}{l}29 \cdot 4 \\
59 \cdot 8\end{array}$ \\
\hline
\end{tabular}


e.g. 4 and $6 \%$ the ill-effects of decreasing the $\mathrm{NH}_{4} \mathrm{NO}_{3}$ concentration was much greater than at the lower glucose level. Thus the dry weight of the $(+)$ strain with $0.025 \mathrm{M}-\mathrm{NH}_{4} \mathrm{NO}_{3}$ and $6 \%$ glucose is $30.2 \mathrm{mg}$., whereas with $2 \%$ glucose it is $48.0 \mathrm{mg}$. compared with the dry weights with $0.0375 \mathrm{M}-\mathrm{NH}_{4} \mathrm{NO}_{3}$ and $2 \%$ or $6 \%$ glucose which were both $64.5 \mathrm{mg}$. There are two possible explanations of this result. Either the rate of utilization of $\mathrm{NH}_{4} \mathrm{NO}_{3}$ is increased with the high glucose concentration and so a low level of $\mathrm{NH}_{4} \mathrm{NO}_{3}$ becomes a limiting factor, or the increased glucose leads to an increased rate of respiration. In view of the fact that such a low dry weight is obtained the latter explanation is perhaps more likely. Table 5 indicates that $2 \%$ glucose combined with $0 \cdot 0375 \mathrm{M}-\mathrm{NH}_{4} \mathrm{NO}_{3}$ gave a satisfactory dry weight for $(+)$ and $(-)$ strains alike.

\section{Fourth factorial analysis}

Talley \& Blank (1941) showed that the important factor governing nutrition in their experiments was the ratio between nutrients and not their absolute quantity. Thus an increase in any salt, if accompanied by a corresponding increase in the other constituents of the media, did not result in a change of dry weight provided the necessary balance was maintained. This fourth factorial experiment was designed to see whether or not this held for M. hiemalis. The absolute quantities of the salts found to be suitable for growth were doubled and halved, the ratio, of one salt to another being maintained. The results expressed as average dry weights are given in Table 6.

Table 6. Dry weights of Mucor hiemalis (+) and (-) strains when quantities of salts were doubled and halved Results given as mg. dry weight

\begin{tabular}{|c|c|c|c|c|}
\hline $\mathrm{NH}_{4} \mathrm{NO}_{3}$ & $\mathrm{MgSO}_{4}$ & $\mathrm{~K}_{2} \mathrm{HPO}_{4}$ & $(+)$ strain & (-) strain \\
\hline $0.01875 \mathrm{M}$ & $0 \cdot 00075 \mathrm{M}$ & $0.006 \mathrm{M}$ & $76 \cdot 12$ & $50 \cdot 4$ \\
\hline $0.0375 \mathrm{M}$ & $0.0015 \mathrm{M}$ & $0.012 \mathrm{M}$ & $64 \cdot 48$ & $64 \cdot 02$ \\
\hline $0.075 \mathrm{M}$ & $0.003 \mathrm{M}$ & $0.024 \mathrm{M}$ & $108 \cdot 02 *$ & $81 \cdot 86^{*}$ \\
\hline
\end{tabular}

* Insoluble phosphate was deposited in the hyphal mesh and is included in these weights.

Again a difference in response between the $(+)$ and $(-)$ strains is seen but the final dry weights obtained when both strains were grown in the medium which had been shown to be well balanced for both the first order interactions were practically the same; there is an average difference of only $0.46 \mathrm{mg}$. The remainder of the results shows an inconsistency which was not unexpected. When the absolute quantities of the salts were balanced there was a marked increase in growth of the $(+)$ strain but there was a characteristic decrease in growth of the $(-)$ strain. When the absolute quantities of the salts were doubled, it was found that insoluble crystals of a phosphate formed within the hyphal mesh which of course vitiated the results at this high concentration. But it is probably true that there was no actual decrease in growth and possibly a little increase above the $64.5 \mathrm{mg}$. obtained for the original combination of salts. 


\section{DISCUSSION AND CONCLUSION}

Experiments of this kind enable one to draw several conclusions which give positive information about the nutritional requirements of the fungus concerned. Although there is no dearth in the literature of examples showing the importance of individual salts and other chemical compounds to fungal growth, there are too few comprehensive analytical reports on this aspect of nutrition. Thus it is probably too early to make generalizations which the future may show to be invalid. It may be concluded that an analysis of the experiments described in this paper shows that at $20^{\circ}$ and with trace elements supplied as impurities in the chemicals used a liquid medium containing $2 \%$ glucose, $0.0375 \mathrm{M}-\mathrm{NH}_{4} \mathrm{NO}_{3}, 0.0015 \mathrm{M}-\mathrm{MgSO}_{4} .7 \mathrm{H}_{2} \mathrm{O}$ and $0.012 \mathrm{M}-\mathrm{K}_{2} \mathrm{HPO}_{4}$ represents a fairly balanced medium and provides the best combination for a good strong growth of $M$. hiemalis. However, while a balance between the salts is necessary for good growth it is impossible to conclude that balance alone is the factor of over-riding importance in the nutrition of this species of Mucor, since a change in quantity whilst keeping the balance the same, as in Exp. 4, gave rather inconsistent results which could not be related to any failure of experimental technique. Thus a halving of quantity gave increased dry weight for the $(+)$ strain and an equally reduced dry weight for the $(-)$ strain as compared with results at the levels used throughout the experiments. This conclusion does not agree with that of Talley \& Blank (1941), who found that balance alone controlled the growth of the parasitic fungus Phymatotrichum omnivorum. It is perhaps significant to note that Mucor is a saprophytic fungus, and this difference in the importance of a balance of mineral nutrients between these two fungi may also be a measure of the difference in their modes of nutrition. The importance of $\mathrm{NH}_{4} \mathrm{NO}_{3}$ in the culture solution is obvious. It seems to serve as the key nutrient in the balance of salts, for the first-order interaction of this salt with each of the others resulted in a definite and precise increase of growth.

\section{REFERENCES}

Pratr, R. (1945). The influence of the proportions of $\mathrm{KH}_{2} \mathrm{PO}_{4}, \mathrm{MgSO}_{4}$ and $\mathrm{NaNO}_{3}$ in the nutrient solution on the production of penicillin in surface culture. Amer. J. Bot. 32, 528.

Raulin, J. (1869). Etudes chimiques sur la végétation. Ann. Ści. nat. Bot. 93, 11.

Robrins, W. J. (1937). The assimilation by plants of various forms of nitrogen. Amer. J. Bot. 24, 243.

Talley, P. J. \& Blank, L. M. (1941). A critical study of the nutritional requirements of Phymatotrichum omnivorum. Plant Physiol. 16, 1.

Young, H. C. \& Bennetr, C. W. (1922). Growth of some parasitic fungi in synthetic culture media. Amer. J. Bot. 9, 559.

(Received 6 May 1953) 